\title{
Scintillating Screens for Micro-Imaging Based on the Ce-Tb Doped LuAP Single Crystal Films
}

\author{
Paul-Antoine Douissard, Thierry Martin, Federica Riva, Eric Mathieu, Yuriy Zorenko, Volodymyr Savchyn, \\ Tanya Zorenko, and Alexander Fedorov
}

\begin{abstract}
Single Crystal Film (SCF) scintillators are key-components of today's high-resolution 2D X-ray detectors used at synchrotrons for applications such as X-ray Radiography, Computed Tomography (CT), laminography, full-field XANES, and topography. Due to its high density and effective atomic number, $\mathrm{LuAlO}_{3}$ (LuAP) perovskite has a great potential to replace or complement the currently used Eu-doped $\mathrm{Gd}_{3} \mathrm{Ga}_{5} \mathrm{O}_{12}$ (GGG:Eu) and Tb-doped $\mathrm{Lu}_{2} \mathrm{SiO}_{5}$ (LSO:Tb) SCFs. In this article we present the growth of LuAP single crystalline films on undoped $\mathrm{YAlO}_{3}$ (YAP) by the vertical dipping isothermal Liquid Phase Epitaxy (LPE) growth method. For the comparison of the light output of Ce and Tb doped LuAP SCF screens both cathodoluminescence $(C L)$ and $X$-ray excited luminescence (RL) measurements were used. For investigations of Ce-Tb energy transfer in the afore mentioned oxide hosts, in addition to using traditional spectroscopic methods, we made time-resolved luminescent spectroscopy of Ce-Tb doped LuAP SCFs under excitation by pulsed synchrotron radiation at the Superlumi station (HASYLAB at DESY). Recently we have demonstrated the strong quenching influence of $\mathrm{Pb}^{2+}$ flux related impurity on the $\mathrm{Ce}^{3+}$ emission in the Ce-doped LuAP SCF screens. However our present investigation shows that Tb-doped LuAP SCFs are efficient $X$-ray scintillators, whose light output can be significantly increased by co-doping with $\mathrm{Ce}^{3+}$ ions. Namely, we demonstrate the efficient $\mathrm{Ce} \rightarrow$ Tb energy transfer in LuAP:Tb,Ce SCFs. Finally, as-grown LuAP:Tb and LuAP:Tb,Ce films were evaluated for high-resolution X-ray imaging using a spatial resolution target at the European Synchrotron Radiation Facility (ESRF), and displayed promising results.
\end{abstract}

Index Terms - Liquid phase epitaxy, LuAP, luminescence, scintillator, single crystal film, X-ray detector, X-ray imaging, YAP.

\section{INTRODUCTION}

$\mathbf{O}$ UR work is related to the development of new types of scintillating screens for 2D/3D micro-imaging [1], [2] based on the rare-earth (RE) doped single crystalline films

Manuscript received May 24, 2013; revised August 06, 2013; accepted August 20, 2013. Date of publication November 01, 2013; date of current version February 06, 2014. The work of Y. Zorenko and T. Zorenko was supported in part by the Polish National Science Center (project No. 2012/07/B/ ST5/02376 and the Ministry of Education and Science of the Ukraine (project No. SF126 F).

P.-A. Douissard, T. Martin, F. Riva and E. Mathieu are with the ESRF, 38043 Grenoble, France (e-mail: douissar@esrf.fr; tmartin@esrf.fr; federica.riva@esrf.fr; emathieu@esrf.fr).

Y. Zorenko is with the Institute of Physics, Kazimierz Wielki University in Bydgoszcz, 85-090 Bydgoszcz, Poland on leave from the Electronics Department, Ivan Franko National University of Lviv, 79017 Lviv, Ukraine (e-mail: zorenko@ukw.edu.pl).

V. Savchyn and T. Zorenko are with the Department of Electronics, Ivan Franko National University of Lviv, 79017 Lviv, Ukraine (e-mail: savchyn. lviv@mail.ru; tanyazorenko@gmail.com).

A. Fedorov is with the Institute for Scintillation Materials NAS of Ukraine, 61000 Kharkiv, Ukraine (e-mail: fedorov@xray.isc.kharkov.com).

Color versions of one or more of the figures in this paper are available online at http://ieeexplore.ieee.org.

Digital Object Identifier 10.1109/TNS.2013.2282181
(SCF) of Lu-based oxide compounds grown by Liquid Phase Epitaxy (LPE) method [3]-[11]. Long image exposure times (up to several seconds), are used with X-ray excited scintillating screens. Therefore in addition to RE ions which have fast d-f luminescence $(\mathrm{Ce}, \mathrm{Pr})$ decay times in the range of several tens of nanoseconds, we can also use the slower RE activators which have dominant $\mathrm{f}-\mathrm{f}$ luminescence with decay times in the range of milliseconds $\left(\mathrm{Tb}^{3+}, \mathrm{Eu}^{3+}\right)$ [3], [4].

Today Eu doped GGG and Tb doped LSO SCFs are the state of the art of scintillating screens [5] used at the ESRF, and their desired properties surpass those of SCFs developed in the past, namely Ce doped YAG and Eu doped LuAG [2].

Due to its high density and effective atomic number, $\mathrm{LuAlO}_{3}$ (LuAP) perovskite is also a promising material for scintillation screens with high X-ray absorption [3], [8], [11]. In this work, we investigate the light yield (LY), luminescent properties and energy transfer processes in the Ce,Tb-doped LuAP SCF with $\mathrm{Ce}^{3+}$ emission in the $\mathrm{UV}$, and $\mathrm{Tb}^{3+}$ emission in the green spectral range.

\section{LPE GROWTH OF CE-TB-DOPED LUAP SCF}

LuAP:Ce and LuAP:Ce,Tb SCF samples were grown by the LPE method onto YAP substrates with (100) and (001) orientations that were obtained from different suppliers. This growth used melt-solutions based on $\mathrm{PbO}-\mathrm{B}_{2} \mathrm{O}_{3}$ fluxes. We did not use any additional doping to decrease misfit $(0.76-1.4 \%)$ between the LuAP SCF and YAP substrates (Fig. 1). The quality of SCF strongly depends on the orientation of the YAP substrate and the value of misfit between the SCF and substrate lattices (Fig. 1).

Recently we found a strong negative influence of the $\mathrm{Pb}^{2+}$ flux dopant on the UV luminescence $\mathrm{LY}$ of $\mathrm{Ce}^{3+}$ ions in SCF of perovskites grown from a $\mathrm{PbO}-\mathrm{B}_{2} \mathrm{O}_{3}$ flux [13]. $\mathrm{Pb}$ contamination is the main reason for the significantly lower LY of Ce-doped LuAP SCF screens in comparison with single crystal counterparts [2] (Table I).

The problem of the low LY of $\mathrm{Ce}^{3+}$ doped LuAP SCF can be eliminated by co-doping these SCF with $\mathrm{Tb}^{3+}$ ions. The $\mathrm{Tb}^{3+}$ ions also have a significantly larger segregation coefficient (about $0.7-1.0)$ in (Y,Lu)AP SCF [13] as compared to $\mathrm{Ce}^{3+}$ ions (about $0.006-0.01$ ) [14]; therefore the ratio $\mathrm{Ce}+$ $\mathrm{Tb}$ activators/Pb impurity in these SCF can be significantly increased. The contribution of the $\mathrm{Ce}^{3+}$ and $\mathrm{Tb}^{3+}$ emissions in the UV and blue ranges for the $\mathrm{Ce}, \mathrm{Tb}$ doped LuAP SCF compounds can be changed by varying the ratio of the $\mathrm{Ce}$ and $\mathrm{Tb}$ ions in the melt-solution and the SCF growth temperature. 


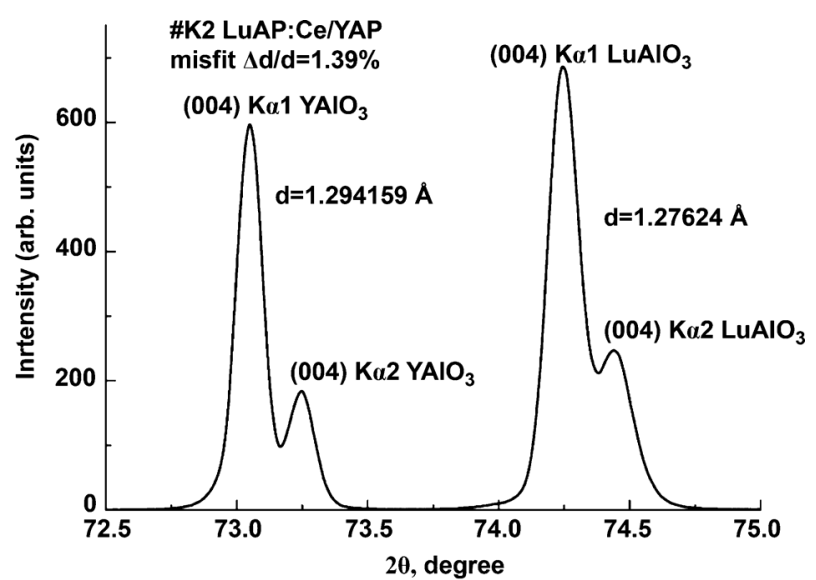

(a)

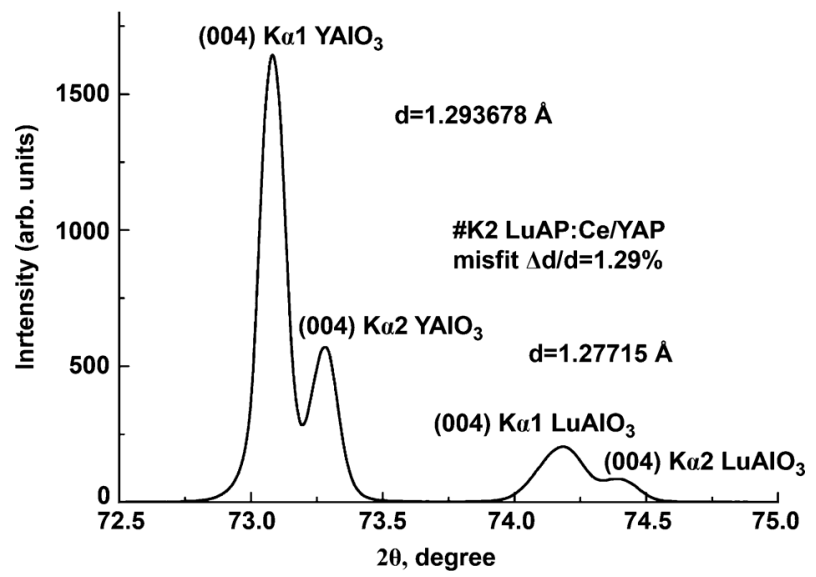

(b)

Fig. 1. XRD pattern of the LuAP (a) and LuAP:Ce,Tb (b) SCFs and YAP substrates.

TABLE I

Relative LY of the Best Samples in a Series of Ce and Tb Doped (Y,LU)SO AND (Y,LU)AP AND (LU,Y)AG BASED SCF SCINTILLATORS. THESE ARE COMPARED TO STANDARD BULK SC ANALOGUES AND A STANDARD YAG:CE SC SAMPLE (THESE ARE ALL INDICATED BY *) UNDER EXCITATION BY $\alpha$-PARTICles of $\mathrm{Pu}^{239}$ SOURCES (5.5 MEV) AND BY X-RAYS $\mathrm{Cu}_{\mathrm{K} \alpha}$, SAMPLES AT $300^{\circ} \mathrm{K}$. n. m. - NOT MEASURED

\begin{tabular}{|c|c|c|c|c|c|}
\hline $\begin{array}{l}\text { Type of } \\
\text { scintillator }\end{array}$ & $\begin{array}{c}\mathrm{Ce} / \mathrm{Tb} \\
\text { content in } \\
\mathrm{SCF}, \text { at. \% }\end{array}$ & $\begin{array}{c}\text { Emission } \\
\text { wavelength } \\
\mathrm{nm}\end{array}$ & $\begin{array}{c}\text { Decay time, } \\
\text { (to } 1 / \mathrm{e} \text { level), } \\
\mathrm{ns}\end{array}$ & $\begin{array}{c}\mathrm{LY} \text { under } \\
\text { excitation by } \\
\mathrm{Pu}^{239} \text { source }\end{array}$ & $\begin{array}{l}\text { LY under } \\
\text { X-ray } \\
\text { excitation }\end{array}$ \\
\hline LuAP:Ce SCF & 0.03 & 378 & 16.8 & 7.65 & 15 \\
\hline LuAP:Tb SCF & 2.2 & 544 & $\sim \mu \mathrm{s}$ & n. m. & 70 \\
\hline $\begin{array}{c}\text { LuAP:Ce,Tb } \\
\text { SCF }\end{array}$ & 2.4 & $358 ; 544$ & n. m. & n. m. & 144 \\
\hline LSO:Tb SCF & 0.9 & 544 & $\sim \mu \mathrm{s}$ & n. $m$. & 100 \\
\hline YAP:Ce SC* & $\sim 0.1$ & 366 & 16.2 & 100 & n. $m$. \\
\hline $\begin{array}{c}\mathrm{Lu}_{0.3} \mathrm{Y}_{0.7} \mathrm{AG}: \mathrm{Ce} \\
\mathrm{SC}^{*}\end{array}$ & $\sim 0.1$ & 375 & 18.1 & 56.3 & n. m. \\
\hline YAG:Ce SC* & 0.25 & $\sim 550$ & $\sim 70$ & 65 & 100 \\
\hline
\end{tabular}

\section{EXPERIMENTAL METHODS}

The luminescent and scintillation properties of $\mathrm{Ce}, \mathrm{Tb}$ co-doped LuAP SCF were compared with the properties of their singly $\mathrm{Ce}$ and $\mathrm{Tb}$ doped counterparts using several methods:

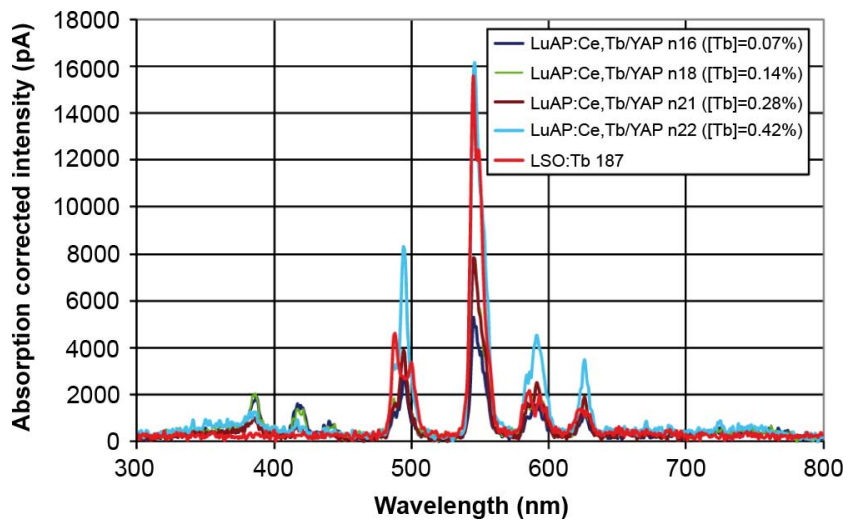

Fig. 2. Dependence of the radioluminescence spectra of the LuAP:Ce,Tb SCF on the concentration of $\mathrm{Tb}^{3+}$ ions in the melt solutions (in molar\%), and comparison with a state of the art LSO:Tb single crystal film.

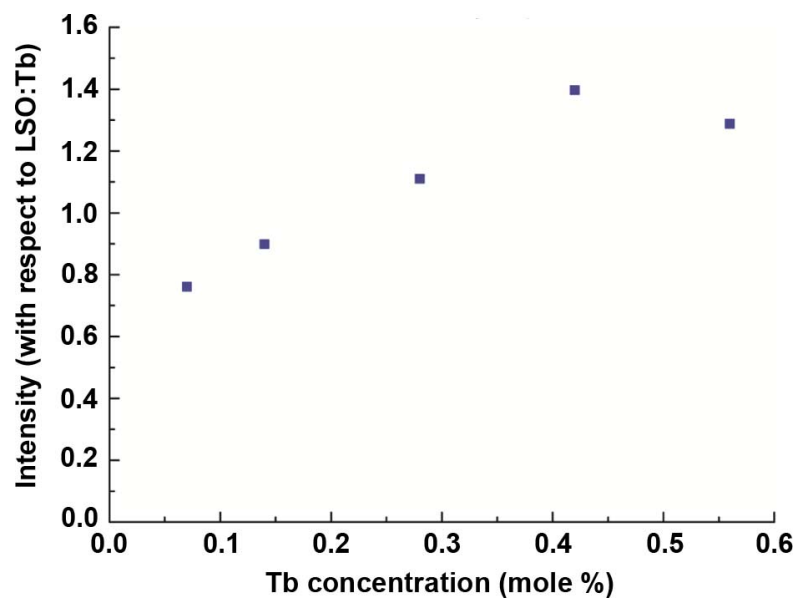

Fig. 3. Dependence of the intensity of X-ray excited luminescence of the LuAP:Ce, Tb SCF on the concentration of $\mathrm{Tb}^{3+}$ ions in the melt solutions, for layers grown at the same growth speed of $\sim 0.5 \mu \mathrm{m} / \mathrm{mn}$.

A) Content of SCF samples under study was determined using a SEM JEOL 6420 electron microscope equipped with JXA-8612 MX setup.

B) Cathodoluminescence (CL) spectra of LuAP:Ce and LuAP:Ce, Tb SCF were measured at $300^{\circ} \mathrm{K}$ with a set-up based on a DMR-4A monochromator and a FEU-106 photomultiplier tube (PMT) under pulsed e-beam excitation (pulse duration of $2 \mu \mathrm{s}$ and frequency of 3-30 $\mathrm{Hz}$ ) with $9 \mathrm{keV}$ electron energy and a beam current of $100 \mu \mathrm{A}$.

C) Scintillation LY was measured using a FEU-110 PMT which has a maximum sensitivity in the $400-450 \mathrm{~nm}$ range, with an amplifier shaping time of $0.5 \mu \mathrm{s}$; in this case the excitation was by $\alpha$-particles from a ${ }^{239} \mathrm{Pu}$ source $(5.5 \mathrm{MeV})$.

D) Light output of SCF luminescence at $300^{\circ} \mathrm{K}$ was measured under X-ray excitation at $8 \mathrm{keV}\left(\mathrm{Cu}_{\mathrm{K} \alpha}\right)$.

E) The excitation spectra in the $225-50 \mathrm{~nm}$ range and the decay kinetics in the 0-200 ns range were measured at $300^{\circ} \mathrm{K}$ with pulsed $(0.127 \mathrm{~ns})$ excitation using synchrotron radiation at the Superlumi station (HASYLAB at DESY). 


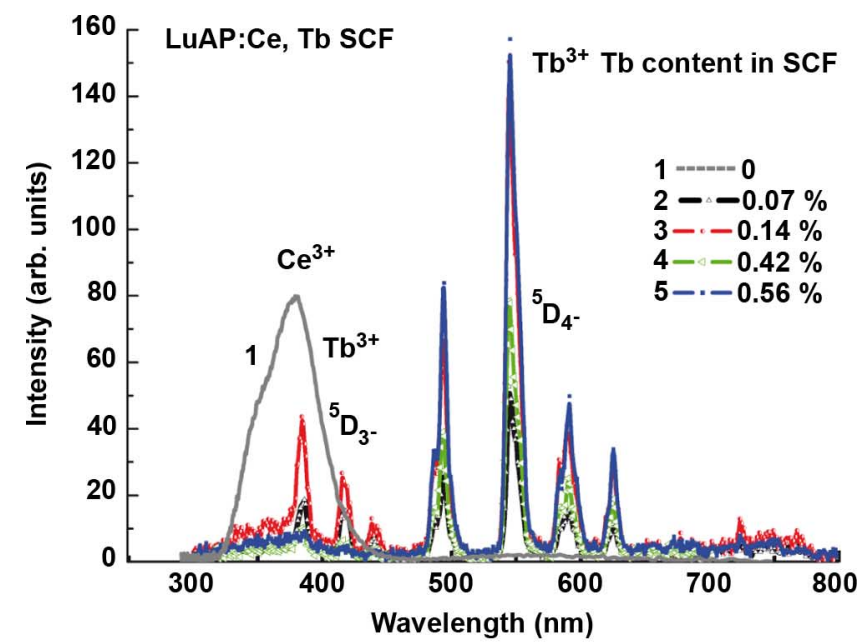

(a)

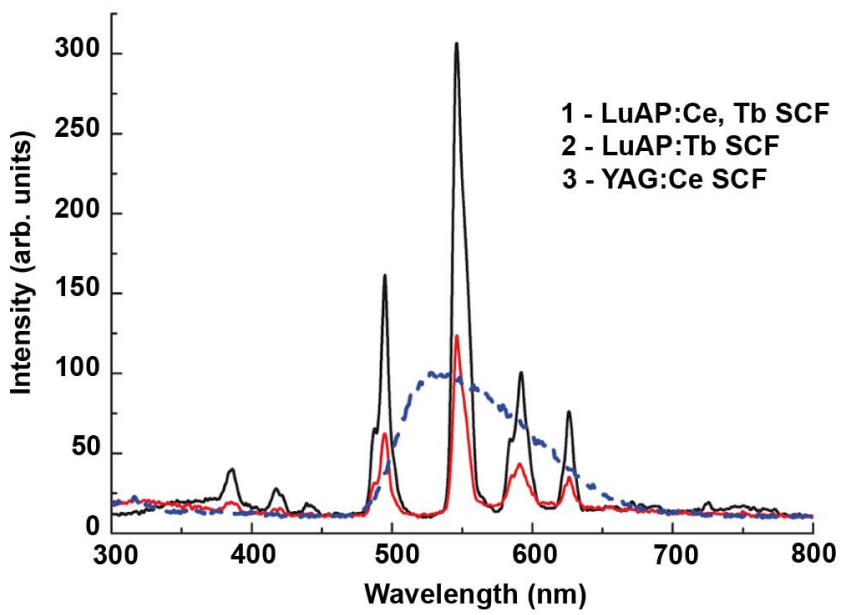

(b)

Fig. 4. (a) - CL spectra of LuAP:Ce SCF (1) and LuAP:Ce,Tb SCF (2-5) grown with different molar contents of Tb activator in MS; (b) - comparison of the intensity of X-ray excited spectra of LuAP:Ce,Tb SCF (1) and LuAP:Ce (2) SCF with a $500 \mu \mathrm{m}$ thick YAG:Ce SC (3).

\section{A. Light Yield of the Ce,Tb Doped LuAp SCF}

To investigate the influence of $\mathrm{Tb}$ dopant on the luminescence and LY of Ce-doped SCF perovskites, we studied the luminescent properties of $\mathrm{Ce}, \mathrm{Tb}$ doped LuAP SCF grown from melt-solution with $\mathrm{CeO}_{2}$ molar content of $20 \%$ and with different $\mathrm{Tb}_{4} \mathrm{O}_{7}$ molar contents in the $0.07-0.56 \%$ range. As can be seen on Figs. 2 and 3, the LY of the X-ray excited luminescence of LuAP:Ce,Tb SCF increases with the Tb molar content in melt-solutions up to $\sim 0.42 \%$, then decreases due to the $\mathrm{Tb}^{3+}$ luminescence concentration quenching (Figs. 2 and 3). From microanalysis of the LuAP:Ce,Tb SCF samples we found that the maximal LY under X-ray excitation was achieved at $\mathrm{Ce}$ and $\mathrm{Tb}$ concentration in the films of $0.05-0.09$ at.\% and $0.4-0.5$ at. $\%$ respectively.

\section{B. Luminescence Properties and Energy Transfer Processes in Ce,Tb Doped LuAP SCF}

The CL spectra of LuAP:Tb SCF present the sharp-line structure of emission of $\mathrm{Tb}^{3+}$ ions in the blue and green ranges that

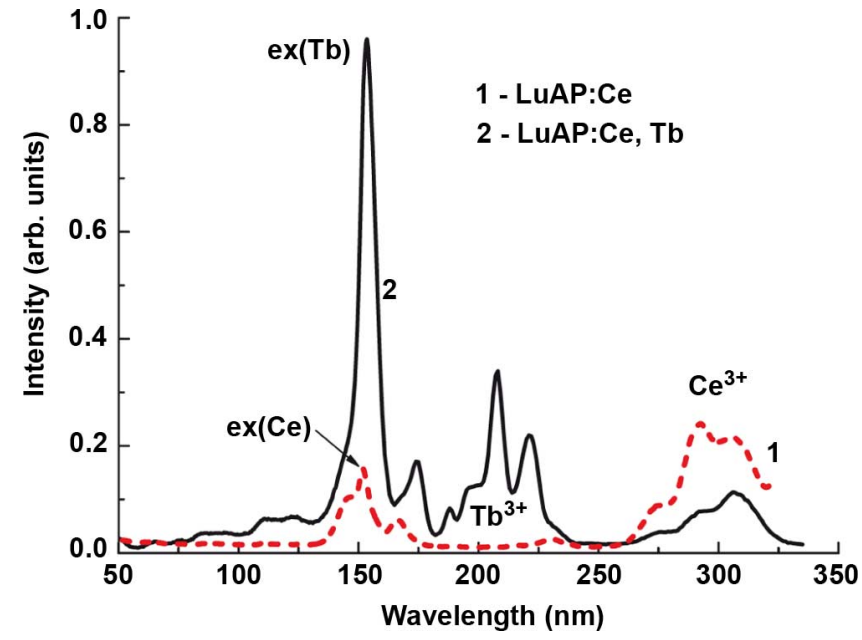

Fig. 5. Excitation spectra of $\mathrm{Ce}^{3+}$ luminescence at $370 \mathrm{~nm}^{2}$ and $\mathrm{Tb}^{3+}$ luminescence at $543 \mathrm{~nm}$ in LuAP:Ce (1) and LuAP:Ce, Tb (2) SCF measured at $300^{\circ} \mathrm{K}$.

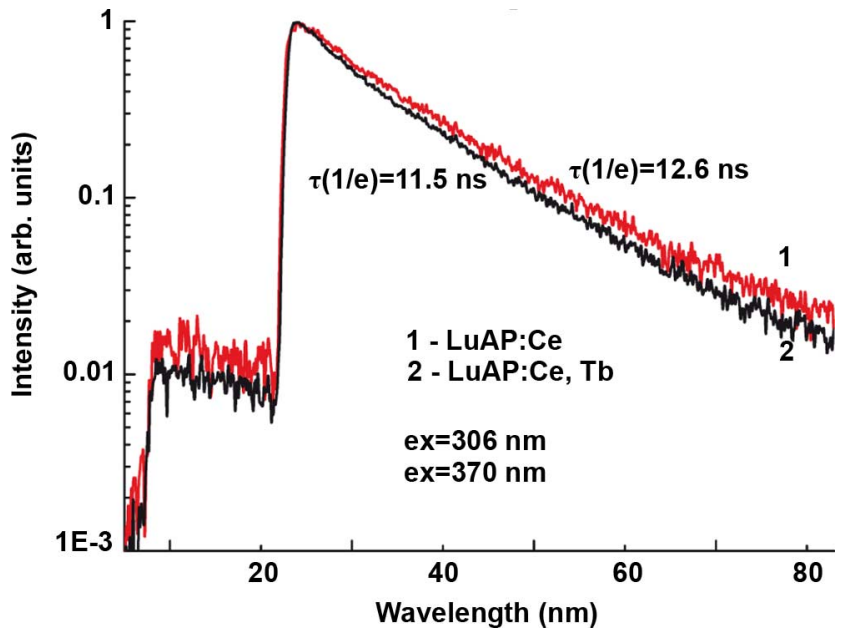

Fig. 6. Decay profiles of $\mathrm{Ce}^{3+}$ luminescence at $370 \mathrm{~nm}$ in LuAP:Ce (1) and LuAP:Ce,Tb (2) SCF under excitation in the $\mathrm{Ce}^{3+}$ absorption band at $293 \mathrm{~nm}$. $\mathrm{T}=300^{\circ} \mathrm{K}$.

are related to the ${ }^{5} \mathrm{D}_{3}-{ }^{7} \mathrm{~F}_{\mathrm{x}}$ and ${ }^{5} \mathrm{D}_{4}-{ }^{7} \mathrm{~F}_{\mathrm{x}}$ transitions respectively (Fig. 4(a)). The CL spectra of LuAP:Ce,Tb SCF present the superposition of the broad, fast $\mathrm{Ce}^{3+}$ luminescence in the UV range with a maximum at $370 \mathrm{~nm}$, and the slow emission of $\mathrm{Tb}^{3+}$ ions in the blue and green ranges (Fig. 4(a)). The blue emission of $\mathrm{Tb}^{3+}$ ions disappears with increasing terbium concentration in the melt-solution due to the cross-relaxation transitions between the ${ }^{5} \mathrm{D}_{3}$ and ${ }^{5} \mathrm{D}_{4}$ radiative levels of the $\mathrm{Tb}^{3+}$ ions (Fig. 4(a)).

In comparison with the CL spectra of LuAP:Ce SCF (Fig. 4(a), curve 1), the intensity of the $\mathrm{Ce}^{3+}$ luminescence in LuAP:Ce,Tb SCF (Fig. 4(a), curves 2-5) is strongly decreased. This observation confirms the existence of an effective $\mathrm{Ce}^{3+} \rightarrow \mathrm{Tb}^{3+}$ energy transfer in LuAP:Ce,Tb SCF which is due to the overlap of the $\mathrm{Ce}^{3+}$ emission and the ${ }^{5} \mathrm{D}_{3}-{ }^{7} \mathrm{~F}_{6}$ transitions of $\mathrm{Tb}^{3+}$ peaked at $383 \mathrm{~nm}$. Due to the $\mathrm{Ce}^{3+} \rightarrow \mathrm{Tb}^{3+}$ energy transfer in the LuAP host, the light output of X-ray excited luminescence of LuAP:Ce,Tb SCF is significantly larger than that of its LuAP:Tb SCF counterpart (Fig. 4(b) and Table I). 


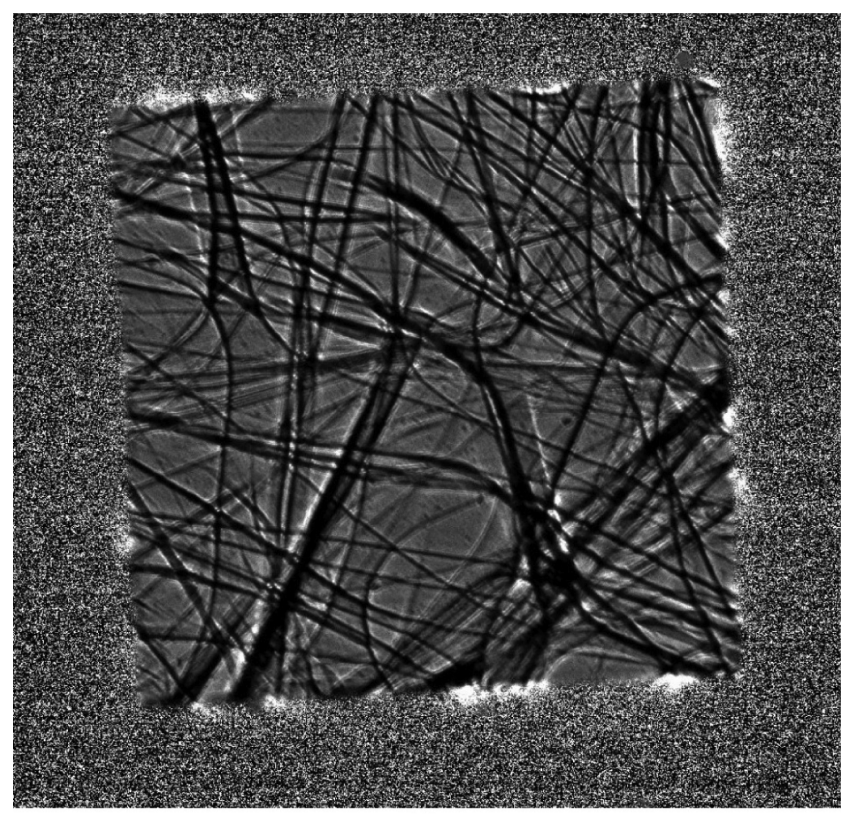

(a)

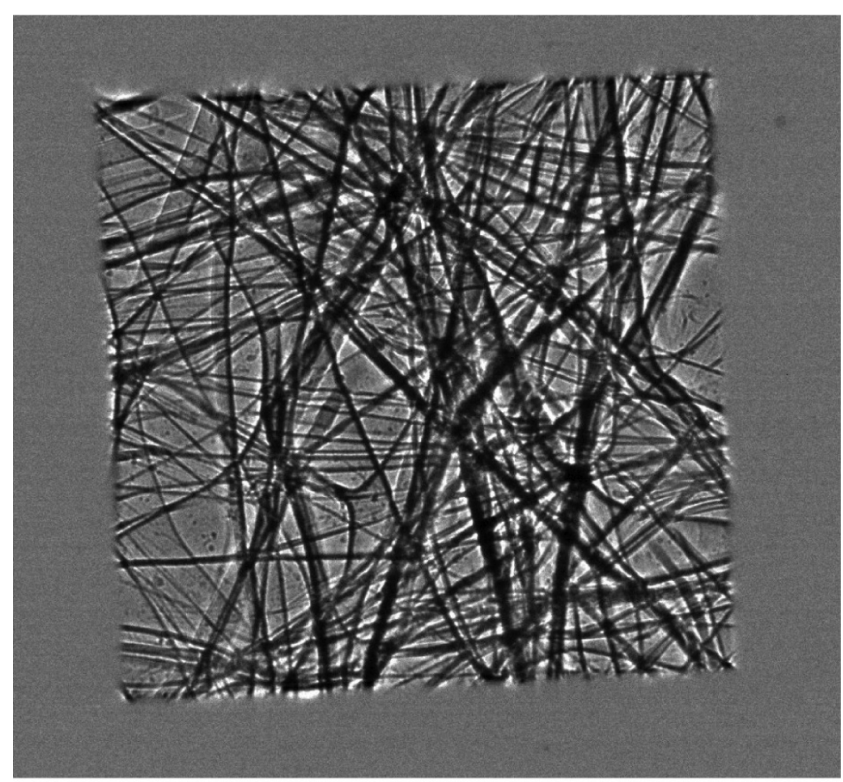

(b)

Fig. 7. a, b. Images of a foam obtained under X-ray at the BM05 beamline at $10 \mathrm{keV}$ with the LuAP:Tb and LuAP:Tb,Ce SCF screens (with SCF thicknesses of 11 and $4.2 \mu \mathrm{m}$, respectively).

This interpretation of the $\mathrm{Ce}^{3+} \rightarrow \mathrm{Tb}^{3+}$ energy transfer mechanism in the LuAP host is confirmed by the excitation spectrum of the $\mathrm{Tb}^{3+}$ luminescence in LuAP:Ce,Tb SCF (Fig. 5, curve 2). In addition to the $\mathrm{Tb}^{3+}$ related to the bands in the VUV and UV ranges at 174, 188, 197, 208 and 221 $\mathrm{nm}$, related to the $4 \mathrm{f}-5 \mathrm{~d}$ transition of $\mathrm{Tb}^{3+}$ ions, this spectrum contains bands peaked at 275,292 and $306 \mathrm{~nm}$, corresponding to the $4 \mathrm{f}-5 \mathrm{~d}$ transition of $\mathrm{Ce}^{3+}$ ions.

The notable increase in the rapidity of the decay kinetics of the $\mathrm{Ce}^{3+}$ luminescence in co-doped LuAP:Ce,Tb SCF (Fig. 6, curve 2) in comparison with the singly doped LuAP:Ce SCF (Fig. 6, curve 1) also confirms this interpretation.

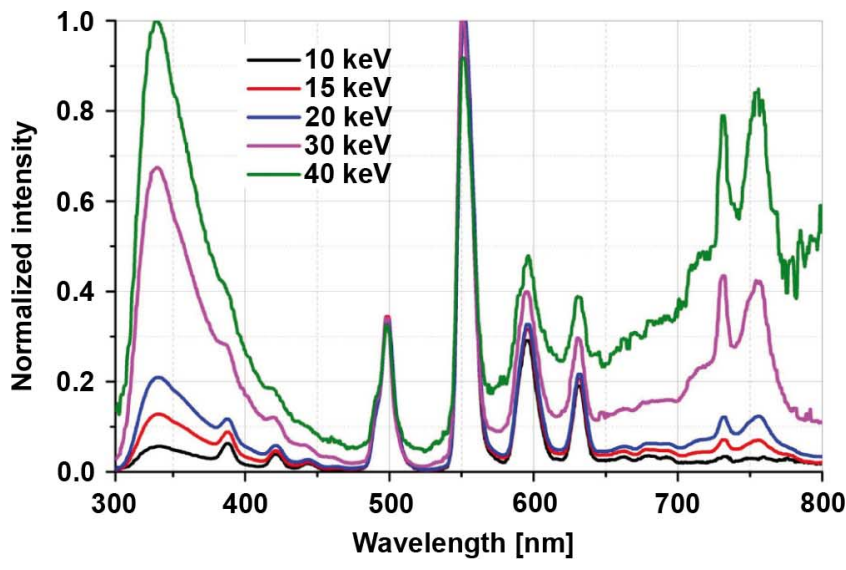

(a)

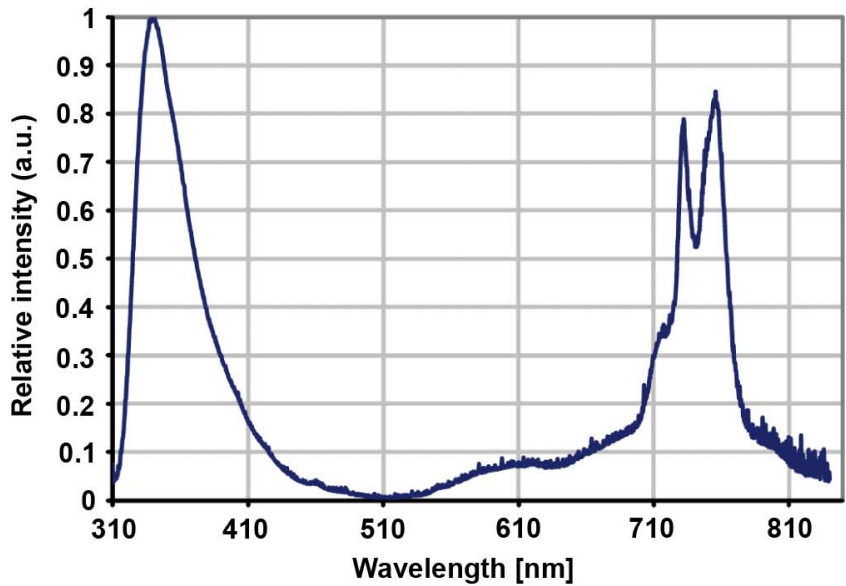

(b)

Fig. 8. (a) Emission spectra for different X-ray excitation energies of a $11 \mu \mathrm{m}$ thin LuAP:Tb SCF grown on a YAP substrate. The intense UV emission band peaked around $340 \mathrm{~nm}$ and the bands in the $700-800 \mathrm{~nm}$ range are related to the luminescence of YAP substrate. (b) For comparison, the emission spectrum of the YAP substrate alone at $30 \mathrm{keV}$.

\section{Visualization of X-RaY IMAges With LuAP:CE,TB SCF SCINTILLATORS}

To demonstrate the application potential of LuAP:Tb and LuAP:Ce,Tb based SCF screens for 2D sub-micro-imaging, we show in Fig. 7 the images of a foam obtained at the ESRF (BM05 beamline) under X-ray excitation at $10 \mathrm{keV}$ using LuAP:Tb (a) and LuAP:Tb,Ce (b) screens with SCF thicknesses of 11 and $4.2 \mu \mathrm{m}$ respectively. The results obtained are very encouraging. The significantly sharpest image was obtained with the thinner LuAP:Tb,Ce SCF sample (Fig. 7(b)) grown on a (001) YAP substrates from Neyco.

Nevertheless, the images were not as sharp as expected. The two main reasons for this are: 1) the screens had two SCF layers (one on each side of the substrate);2) the screens showed parasitic luminescence coming from the thick YAP substrate. Both effects degraded the spatial resolution. This is illustrated in Fig. 8(a) where the emission spectrum of a $11 \mu \mathrm{m}$ thick LuAP:Tb layer deposited on a $400 \mu \mathrm{m}$ thick YAP substrate is recorded for $\mathrm{X}$-ray energies between $10 \mathrm{keV}$ to $40 \mathrm{keV}$. As the X-ray energy is increased, more X-ray photons reach the substrate, which results in a larger parasitic signal contribution. 


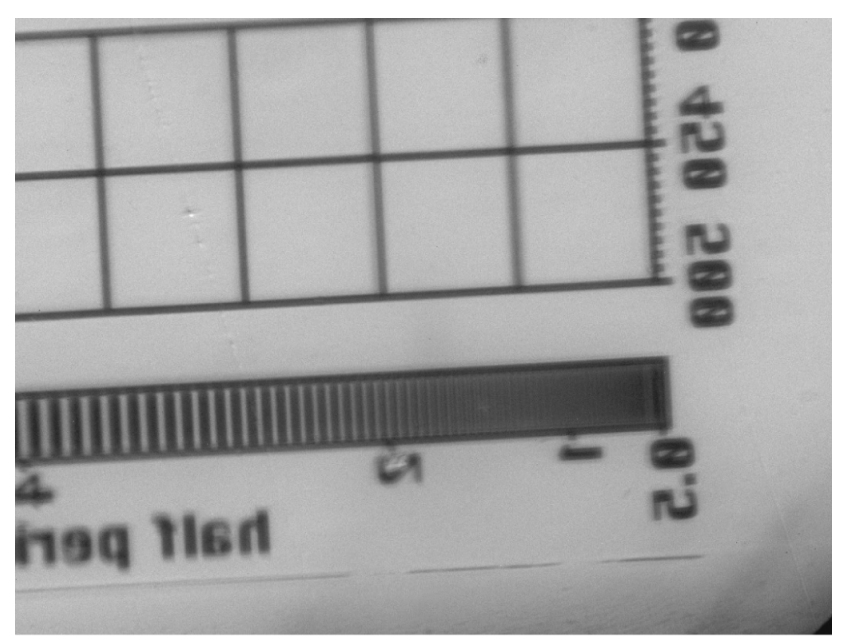

(a)

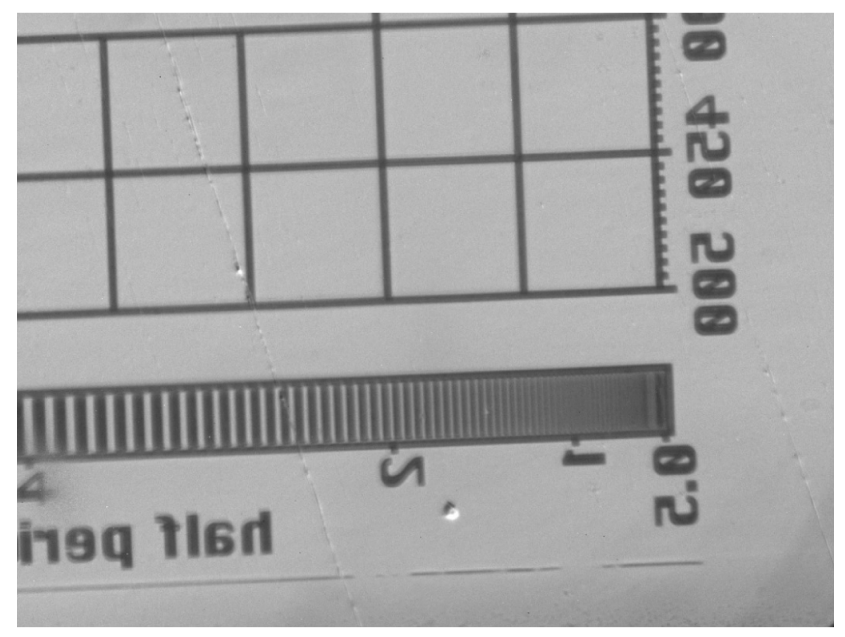

(b)

Fig. 9. Image of an X-radia X-500-200-30 target obtained under 15keV X-ray at the BM05 beamline with the LuAP:Tb,Ce SCF screens $(4.2 \mu \mathrm{m}$ thick). (a) Image obtained without optical filter. (b) Image obtained with an optical filter (FD1G/Thorlabs) used to cut the parasitic UV emission coming from the substrate.

To confirm this last point, Fig. 9(a) shows an X-radia target (X500-200-30) image which we acquired at $15 \mathrm{keV}$ with the LuAP:Tb,Ce screen, using a 40x microscope objective (numerical aperture 0.5 ) coupled to a PCO1600 CCD camera. We repeated the measurement after adding a FD1G optical filter (from Thorlabs) in the detector optical path in order to cut the parasitic emission form the substrate (Fig. 9(b)). The FD1G band pass dichroic filter selects only the main emission of the LuAP:Tb layer at 550nm. With this filter we obtain a net improvement of the image sharpness: the contrast at $500 \mathrm{lp} / \mathrm{mm}$ is more than doubled. The spatial resolution limit expected with this optics and CCD camera is close to $0.7 \mu \mathrm{m}$.

We have demonstrated that it is desirable to have non-luminescent substrates for producing LuAP based layers, or a substrate with an emission wavelength range distinct from that of the SCF layer. Perovskites such as YAP, LuAP and LuYAP possess strong intrinsic luminescence due to oxygen vacancies and antisite defects [15], [16], with a main emission band in the UV but also with strong luminescence in the visible range
(Fig. 8(b)). At present we are seeking substrates with reduced emission in the visible range, since the UV emission, which does not overlap with emission lines from $\mathrm{Eu}^{3+}$ and $\mathrm{Tb}^{3+}$ ions, can be cut with an optical filter.

\section{CONCLUSION}

$\mathrm{Ce}-\mathrm{Tb}$ co-doping is very effective for improvement of the light output and performance of scintillating screens based on LuAP perovskites under X-ray excitation. Such screens can simultaneously emit in the UV and green ranges. The contribution of emission in each of these ranges can be changed by the total $\mathrm{Tb}^{3+}$ content in the melt-solution and by the ratio between the $\mathrm{Ce} / \mathrm{Tb}$ ions in the SCF using different crystallization temperatures.

Based on the results obtained, we show in this work the presence of an effective $\mathrm{Ce} \rightarrow \mathrm{Tb}$ energy transfer in LuAP SCF. Due to the strong contribution of the $\mathrm{Tb}^{3+}$ emission and this effective $\mathrm{Ce}-\mathrm{Tb}$ energy transfer, at the optimal ratio of $\mathrm{Ce} / \mathrm{Tb}$ ions the total LY of the X-ray excited luminescence of $\mathrm{Ce}, \mathrm{Tb}$ doped LuAP SCFs is two times larger than for LuAP:Tb SCF, and 30-40\% larger than that of a bulk YAG:Ce standard sample.

Using LuAP:Tb and LuAP:Tb,Ce SCF screens, good quality images of foam and X-ray target test objects were obtained. Significantly sharper images were obtained with the LuAP:Tb,Ce SCF screens in comparison with LuAP:Tb SCF screens.

The luminescence properties of the LuAP:Tb,Ce single crystalline film scintillators are very promising, but the optical quality of the layers is still to be improved. These layers currently present many striation lines due to the substrate/layer misfit. Adjusting the lattice mismatch between the thin LuAP layers and the YAP substrate may be envisaged, or finding an alternative substrate for the growth of LuAP based screens.

\section{ACKNOWLEDGMENT}

The authors thank E. Ziegler and his team on the ESRF BM05 beamline for making possible the acquisition of the high-resolution X-ray test images. The measurements of decay kinetics at Superlumi station (HASYLAB at DESY) were performed in the framework of the I-20110938 EC project.

\section{REFERENCES}

[1] A. Koch, C. Raven, P. Spanne, and A. Snigirev, "X-ray imaging with sub-micrometer resolution employing transparent luminescent screens," J. Opt. Soc. Am., vol. A 15, pp. 1940-1951, 1998.

[2] A. Koch, F. Peyrin, P. Heurtier, B. Chambaz, B. Ferrand, W. Ludwig, and M. Couchaud, "An X-ray camera for computed microtomography of biological samples with micrometer resolution using $\mathrm{Lu}_{3} \mathrm{Al}_{5} \mathrm{O}_{1} 2$ and $\mathrm{Y}_{3} \mathrm{Al}_{5} \mathrm{O}_{1} 2$ scintillators," Proc. SPIE, vol. 3659, pp. 170-179, 1999.

[3] T. Martin and A. Koch, "Recent development in X-ray imaging with micrometer spatial resolution," J. Synchrotron Rad., vol. 13, pp. 180-194, 2006.

[4] T. Martin, P.-A. Douissard, M. Couchaud, A. Cecilia, T. Baumbach, K. Dupré, and A. Rack, "LSO-based single crystal film scintillator for synchrotron-based hard X-ray micro-imaging," IEEE Trans. Nucl. Sci., vol. 56, pp. 1412-1418, 2009.

[5] P.-A. Douissard, A. Cecilia, X. Rochet, X. Chapel, T. Martin, T. V. D. Kamp, L. Helfen, T. Baumbach, L. Luquot, X. Xiao, J. Meinhardt, and A. Rack, "A versatile indirect detector design for hard X-ray microimaging," J. Instrum., vol. 7, no. Issue 9, p. 09016, 2012. 
[6] P.-A. Douissard, A. Cecilia, T. Martin, V. Chevalier, M. Couchaud, T. Baumbach, K. Dupré, M. Kühbacher, and A. Rack, "A novel epitaxially grown LSO-based thin-film scintillator for micro-imaging using hard synchrotron radiation,"J. Synchrotron Rad., vol. 17, pp. 571-583, 2010.

[7] A. Cecilia, A. Rack, P.-A. Douissard, T. Martin, T. D. S. Rolo, P. Vagoviá, E. Hamann, T.V.D Kampa, A. Riedel, M. Fiederle, and T. Baumbach, "LPE grown LSO:Tb scintillator films for high-resolution $\mathrm{X}$-ray imaging applications at synchrotron light sources," NIM, vol. 648, pp. S321-S323, 2011.

[8] Z. Yu, V. Gorbenko, M. Nikl, J. A. Mares, T. Martin, and P.-A Douissard, "Development of novel UV emitting single crystalline film scintillators," IEEE Trans. Nucl. Sci., vol. 57, pp. 1335-1342, 2010.

[9] Z. Yu, M. Nikl, V. Gorbenko, V. Savchun, T. Voznyak, R. Kucerlova, O. Sidletskiy, B. Grynyov, and A. Fedorov, "Growth and luminescent properties of $\mathrm{Lu}_{2} \mathrm{SiO}_{5}$ and $\mathrm{Lu}_{2} \mathrm{SiO}_{5}$ : Ce single crystalline films," Opt. Mater., vol. 33, pp. 846-852, 2011.

[10] Z. Yu, V. Gorbenko, V. Savchyn, T. Voznyak, B. Grinyov, O. Sidletskiy, D. Kurtsev, A. Fedorov, V. Baumer, M. Nik1, J. A. Mares, A. Beitlerova, and M. Kucera, "Growth and luminescent properties of $\mathrm{Lu}_{2} \mathrm{SiO}_{5}$ : $\mathrm{Ce}$ and $\left(\mathrm{L}_{1-\mathrm{x}} \mathrm{Gd}_{\mathrm{x}}\right) 2 \mathrm{SiO}_{5}$ : Ce single crystalline films," J. Crystal Growth, vol. 337, pp. 72-80, 2011.

[11] Z. Yu, V. Gorbenko, V. Savchyn, T. Voznyak, O. Sidletskiy, B. Grinyov, M. Nikl, J. A. Mares, T. Martin, and P.-A Douissard, "Single crystalline film scintillators based on the orthosilicate, perovskite and garnet compounds," IEEE Trans. Nucl. Sci., vol. 59, no. 5, pp. $2260-2268,2012$.
[12] Z. Yu, V. Gorbenko, V. Savchyn, T. Voznyak, V. V. Gorbenko, M. Nikl, J. A. Mares, O. Sidletskiy, B. Grinyov, A. Fedorov, K. Fabisiak, and K. Paprocki, "Scintillation and luminescent properties of undoped and $\mathrm{Ce}^{3+}$ doped $\mathrm{Y}_{2} \mathrm{SiO}_{5}$ and $\mathrm{Lu}_{2} \mathrm{SiO}_{5}$ single crystalline films grown by LPE method," Opt. Mater., vol. 34, pp. 1969-1974, 2012.

[13] Z. Yu and V. Gorbenko, "Growth and luminescence properties of single crystalline films of $\mathrm{RALO}_{3}(\mathrm{R}=\mathrm{Lu}, \mathrm{Lu}-\mathrm{Y}, \mathrm{Y}, \mathrm{Tb})$ perovskites," Physics of Solid State, vol. 51, pp. 1800-1808, 2009.

[14] Z. Yu, M. Nikl, J. A. Mares, V. Gorbenko, V. Savchyn, T. Voznyak, M. Kucera, A. Beitlerova, R. Kucerkova, and A. Fedorov, "The luminescent and scintillation properties of $\mathrm{YALO}_{3}$ and $\mathrm{YALO}_{3}$ : Ce single crystalline films grown by liquid phase epitaxy from BaO-based flux," Phys. Stat. Sol (a), vol. 206, pp. 2586-2592, 2009.

[15] Y. Zorenko, V. Gorbenko, A. Voloshinovskii, V. Vistovskii, M. Nikl, E. Mihokova, and K. Nejezchleb, "Intrinsic and $\mathrm{Ce}^{3}$ +-related luminescence of single crystals and single crystalline films of YAP perovskites: New results," IEEE Trans. Nucl. Sci., vol. 55, pp. 1186-1191, 2008.

[16] Y. Zorenko, V. Gorbenko, T. Voznyak, V. Mikhailin, V. Kolobanov, D. Spassky, and M. Nikl, "Intrinsic and $\mathrm{Ce}^{3}+$-related luminescence in single crystalline films and single crystals of LuAp and LuAp:Ce perovskites," IEEE Trans. Nucl. Sci., vol. V.55, pp. 1192-1196, 2008. 